\title{
Psyche and soma interactions: the paradigm of depression George Christodoulou*
}

Address: Professor of Psychiatry and President of the Hellenic Psychiatric Association, Greece

* Corresponding author

\author{
from International Society on Brain and Behaviour: 2nd International Congress on Brain and Behaviour \\ Thessaloniki, Greece. 17-20 November 2005 \\ Published: 28 February 2006 \\ Annals of General Psychiatry 2006, 5(SuppI I):SI5 doi:10.II86/I744-859X-5-SI-SI5
}

Psyche and soma cross-talk and interact in a variety of ways and degrees. Similarly, psychopathology and somatic pathology interact, coincide or overlap. Additionally, they may undergo reciprocal interchanges and metamorphoses. The most protean ones are those occurring in depression.

Depression can be expressed clinically in a variety of ways, from the classical symptomatology of which the basic symptom is excessive grief to the non-depression variety and even to the phenomenologically incongruous "smiling" depression.

Insomnia, anorexia, hypo-salivation and constipation are the most typical somatic manifestations of depression. Sexual problems (libidinal and erection dysfunctions) and "hypochondriacal" symptoms (low back pain, headache) are also very frequent.

Conditions frequently co-occuring with depression and probably aetiologically associated with them like substance abuse, alcoholism and polypharmacy are of special clinical importance. Similarly, calamities that may occur in one's life, like, for example, traffic accidents, loss of occupation, divorce, unsatisfactory response to life challenges etc may be caused or at least precipitated by depression or, conversely, may produce or precipitate depression.

These, broadly speaking, psychosomatic interactions and the somatic masks under which depression is hiding should draw the attention of primary care physicians, relatives and community agents (educators, priests, employers, armed and police forces, jurists, the mass media etc) and mental health promotion programs for the creation of alliances in the community should be implemented within the framework of a long-lasting and possibly perpetual preventive effort. 